\title{
Thermally stimulated luminescence studies in combustion synthesized polycrystalline aluminum oxide
}

\author{
K R NAGABHUSHANA, B N LAKSHMINARASAPPA*, D REVANNASIDDAIAH ${ }^{\dagger}$ and \\ FOURAN SINGH ${ }^{\dagger \dagger}$ \\ Department of Physics, Bangalore University, Bangalore 560 056, India \\ ${ }^{\dagger}$ Department of Studies in Physics, University of Mysore, Mysore 570 006, India \\ ${ }^{\dagger \dagger}$ Inter University Accelerator Centre, Aruna Asaf Ali Marg, New Delhi 110 067, India
}

MS received 21 July 2007; revised 5 April 2008

\begin{abstract}
Synthesis of materials by combustion technique results in homogeneous and fine crystalline product. Further, the technique became more popular since it not only saved time and energy but also was easy to process. Aluminum oxide phosphor was synthesized by using urea as fuel in combustion reaction. Photoluminescence (PL) and thermally stimulated luminescence (TSL) characteristics of $\gamma$-irradiated aluminum oxide samples were studied. A broad PL emission with a peak at $\sim 465 \mathrm{~nm}$ and a pair of strong and sharp emissions with peaks at 679 and $695 \mathrm{~nm}$ were observed in $\gamma$-rayed samples. The PL intensity was observed to increase with increase in $\gamma$-ray dose. Two prominent and well resolved TSL glows with peaks at $210^{\circ} \mathrm{C}$ and $365^{\circ} \mathrm{C}$ were observed in all $\gamma$-irradiated $\mathrm{Al}_{2} \mathrm{O}_{3}$ samples. The TSL intensity was also found to increase with increase in $\gamma$-ray dose. The TSL glow curves indicated second order kinetics.
\end{abstract}

Keywords. Photoluminescence; thermoluminescence; gamma irradiation; colour centres.

\section{Introduction}

Thermally stimulated luminescence (TSL), also called thermoluminescence (TL), is extensively used as a technique in dosimetry. The energy absorbed by a phosphor on being exposed to some ionizing radiation is released as light on subsequently heating it. The intensity of light emitted by the phosphor on being heated gives an idea of the concentration of defect centres caused by the interaction of ionizing radiation with matter. Further, TSL is a convenient technique to understand the charge trapping and detrapping mechanisms that result from the interaction of the radiation with the existing defects in material. However, there is no simple model or explanation for TSL mechanism because of the wide variety of processes involved. Aluminum oxide was one of the earlier materials studied for its possible application as a radiation dosemeter owing to its superior thermal and chemical stability and low effective atomic number (Rieke and Daniels 1957). Further, it is a highly sensitive luminescence dosemeter material and it has been the subject of many studies in thermo and optically stimulated luminescence. It constitutes a class of TSL phosphors with good performance, especially when doped with carbon. A good

\footnotetext{
*Author for correspondence (bnlnarasappa@gmail.com)
}

amount of work on TSL of transparent $\mathrm{Al}_{2} \mathrm{O}_{3}$ and $\mathrm{Al}_{2} \mathrm{O}_{3}$ :C crystals have been reported (Summers 1984; McKeever et al 1999; Chithambo et al 2002). The powder form of this phosphor has some special advantages such as good flexibility of dosimeter size, shape etc. Synthesis of oxide phosphors has been achieved by a variety of routes such as solid-state reactions, sol-gel techniques (Rao 1993), hydroxide precipitation (Kinsman et al 1994), hydrothermal synthesis (Veitch 1991) and combustion synthesis (Kingsley and Patil 1988; Zhang and Stangle 1994). Combustion synthesis is particularly an easy, safe and rapid production process besides energy and time savings. This quick, straightforward process can be used to produce homogeneous, high-purity, crystalline oxide ceramic powders (Kingsley and Patil 1988). The preparation of aluminum oxide by combustion process using different fuels results in different particle sizes. For example, if glycine and hydrazine are used as fuels they yield nanoparticles (Mimani and Patil 2001). The grain size affects the sensitivity, dose response and other parameters of TSL glow curves. A good compromise is to use powders with grain sizes between 75 and $200 \mu \mathrm{m}$ (Bos 2001). In the present investigation, urea is used as fuel which yields polycrystalline aluminum oxide. The objective of our present investigation is to understand the photoluminescence (PL) and thermoluminescence behaviours of combustion synthesized polycrystalline $\gamma$-irradiated aluminum oxide. 


\section{Experimental}

Polycrystalline aluminum oxide was synthesized by combustion technique based on the procedure described elsewhere (Nagabhushana et al 2007). As synthesized aluminum oxide was grained into a fine powder using an agate mortar and $50 \mathrm{mg}$ of each sample was weighed using a digital balance (Sartorius) with $\pm 0.1 \mathrm{mg}$ accuracy. These samples were packed in black paper and were irradiated with $\gamma$-rays $\left({ }^{60} \mathrm{Co}\right)$ for the dose ranging from 1.251 to $7.527 \mathrm{KGy}$. PL studies were performed using excitation at $325 \mathrm{~nm}$ light from $\mathrm{He}-\mathrm{Cd}$ laser (KIMMON) and Mechelle900 spectrograph in the range 200-1100 nm wavelength region. The PL setup had a cooled CCD array-based detection system. The laser light was made to incident on the sample at $45^{\circ}$ and the luminescence light was collected using a collector assembly and transmitted to the spectrograph through optical fibre for detection and analysis. The TSL measurements were carried out at a heating rate of $5^{\circ} \mathrm{Cs}^{-1}$ using PC based TSL analyser system (Nucleonix Systems Pvt. Ltd., Hyderabad, India).

\section{Results and discussion}

Photoluminescence emission spectra of combustion synthesized pristine and $\gamma$-irradiated polycrystalline aluminum oxide are shown in figure 1. A broad and weak emission in the range 425-600 $\mathrm{nm}$ and a pair of sharp emissions with peaks at 679 and $695 \mathrm{~nm}$ are observed in both pristine as well as $\gamma$-rayed samples. The sharp emissions are commonly known as $R 1$ and $R 2$ (doublet) lines of $\mathrm{Cr}^{3+}$ impurity substituting $\mathrm{Al}$ site in aluminum oxide and they are assigned to a well known radiative transition ${ }^{2} E \rightarrow{ }^{4} A_{2}$ of substitutional $\mathrm{Cr}^{3+}$ ions (Toyoda et al 1998). When the samples are exposed to $\gamma$-rays, PL emission at 679 and

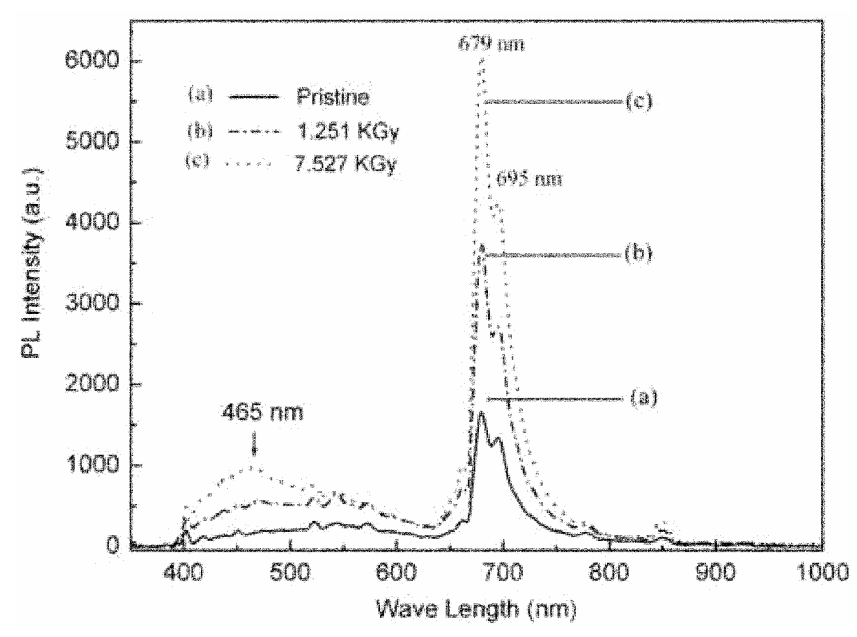

Figure 1. Photoluminescence emission $\left(\lambda_{\mathrm{ex}}=320 \mathrm{~nm}\right)$ spectra of combustion synthesized pristine and $\gamma$-irradiated polycrystalline aluminum oxide.
$695 \mathrm{~nm}$ is enhanced besides a well resolved blue emission at $\sim 465 \mathrm{~nm}$. The $\sim 465 \mathrm{~nm}$ emission may be attributed to $F_{2}^{+}$-centres (two oxygen vacancies with three electrons) (Nagabhushana et al 2007). Further, the intensity of $R$ lines in pristine sample is observed to be lower when compared to that in $\gamma$-rayed ones. It is believed that the increase in emission intensity of $R$ line might be due to re-absorption of $465 \mathrm{~nm}$ light into the absorption bands of the $\mathrm{Cr}^{3+}$ ions (McKeever et al 1999).

Figure 2 shows the thermostimulated luminescence glow curves of combustion synthesized aluminum oxide $\gamma$-irradiated for doses in the range 1.251-7.527 KGy. The glow curves clearly show two well resolved and well separated TSL glow peaks, one at $210^{\circ} \mathrm{C}\left(T_{\mathrm{g} 1}\right)$ and another at $365^{\circ} \mathrm{C}\left(T_{\mathrm{g} 2}\right)$. Zhang and coworkers (Zhang et al 2006) studied TSL and optical absorption (OA) of pure $\alpha-\mathrm{Al}_{2} \mathrm{O}_{3}$ crystals under $\gamma$-irradiation. They reported the OA bands with peaks at 205 and $230 \mathrm{~nm}$ and they were attributed to $F$-centre and $F^{+}$-centres, respectively. Further, the TSL of $100 \mathrm{~Gy} \gamma$-rayed samples showed a TSL glow with peak at $210^{\circ} \mathrm{C}$ and they attributed it to the relaxation of the $F$-centre electron from 3P excited state to the $1 \mathrm{~S}$ ground state (Zhang et al 2006). The first TSL glow with peak at $210^{\circ} \mathrm{C}$ observed in the present work may be attributed to the $F$-centres. Kortov et al (2004) recorded TSL of electron irradiated $\mathrm{Al}_{2} \mathrm{O}_{3}$ in the temperature range $327-527^{\circ} \mathrm{C}$. This high temperature glow peak was attributed to the presence of deep traps which are oxygen vacancies produced in the anion sublattice of aluminum oxide by ionizing radiation (Kortov et al 2004). In the present investigations, it is believed that $F_{2}^{+}$-centre is responsible for this high temperature glow peak. However, it should be mentioned that this point needs more detailed investigations using other techniques such as thermostimulated conductivity, thermoluminescence emission, electron spin

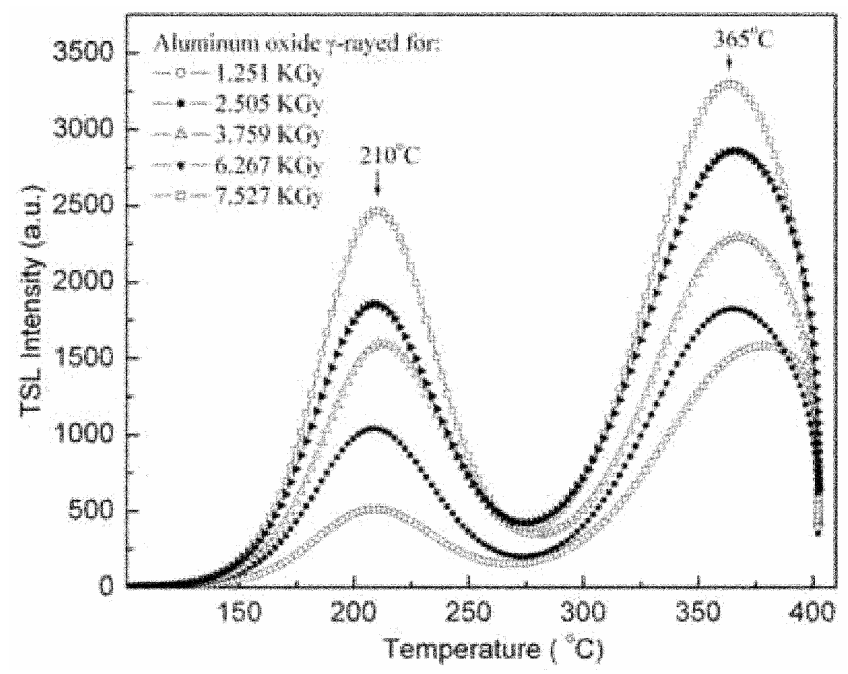

Figure 2. Thermostimulated luminescence glow curves of combustion synthesized $\gamma$-irradiated aluminum oxide $\left(\beta=5^{\circ} \mathrm{Cs}^{-1}\right)$. 
resonance, photoacoustic studies/optical absorption etc in order to understand the TSL mechanism leading to generation and trapping of defect centres due to ionizing radiation and light emission in aluminum oxide during thermal stimulation.

Figure 3 shows the variation of TSL intensity with $\gamma$ ray dose in combustion synthesized aluminum oxide. It is found that the TSL intensity in combustion synthesized alumina increases linearly with increase in dose. The low temperature glow peak $\left(T_{\mathrm{gl}}\right)$ temperature is observed to be steady for the entire range of $\gamma$-ray dose. That is, no peak shift was observed at low temperature TSL peak $\left(T_{\mathrm{gl}}\right)$. But, it is observed that the high temperature TSL glow peak $\left(T_{\mathrm{g} 2}\right)$ slightly shifts towards lower temperature side with increase in $\gamma$-ray dose as can be seen from figure 3 . However, from the glow curves, it is observed that the area under the $T_{\mathrm{g} 1}$ and $T_{\mathrm{g} 2}$ increases linearly with increase in $\gamma$-ray dose. The shift in TSL glow peak position and width might be due to the occupancy of deep traps, since a step annealing procedure gradually shifts the peak back to the original position. The physics of changes in the peak temperature are yet to be understood, but part of the shift to low temperature at high doses may be attributed due to the kinetics of processes as suggested by Yukihara and coworkers (Yukihara et al 2004).

The evaluation of kinetic parameters known as trapping parameters, i.e. activation energy $(E)$ of the traps involved in TSL emission, order of kinetics $(b)$ and frequency factor $(s)$ associated with the glow peaks of TSL are important aspects of TSL studies. Any complete

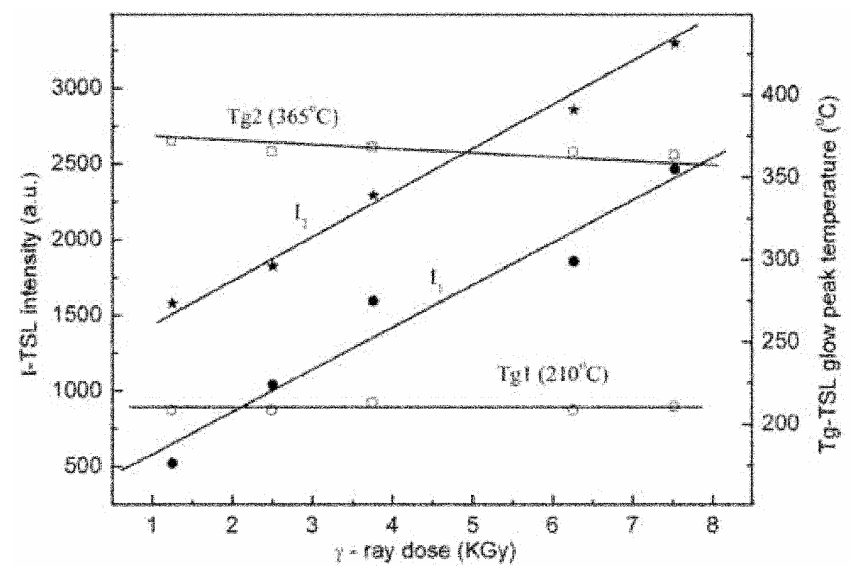

Figure 3. Variation of TSL intensity and TSL glow peak temperature with $\gamma$-ray dose in combustion synthesized aluminum oxide $\left(\beta=5^{\circ} \mathrm{Cs}^{-1}\right)$.

Table 1. Kinetic parameters of as prepared aluminum oxide irradiated with $\gamma$-rays for $7.527 \mathrm{KGy}$ obtained by using the glow curve shape method (modified by Chen).

\begin{tabular}{cccccc}
\hline$T_{\mathrm{g}}$ & $T_{\mathrm{m}}\left({ }^{\circ} \mathrm{C}\right)$ & $\mu_{\mathrm{g}}$ & $b$ & $E(\mathrm{eV})$ & $S\left(\mathrm{~s}^{-1}\right)$ \\
\hline 1 & 210 & 0.51 & 2 & 1.01 & $7.51 \times 10^{9}$ \\
2 & 365 & 0.49 & 2 & 1.52 & $2.68 \times 10^{11}$ \\
\hline
\end{tabular}

description of the TSL characteristics of TSL material requires the knowledge of these parameters. To determine the order of kinetics, the form factor (symmetry factor), $\mu_{\mathrm{g}}$, $\left[\mu_{\mathrm{g}}=\left(T_{2}-T_{\mathrm{m}}\right) /\left(T_{2}-T_{1}\right)\right]$, which involves $T_{1}$ and $T_{2}$ are calculated where these are the temperature corresponding to the half of the maximum intensities on either side of the glow peak maximum $\left(T_{\mathrm{m}}\right)$. Theoretically, form factor which ranges between 0.42 and 0.52 , is close to 0.42 for first order kinetics and 0.52 for second order kinetics (Horowitz et al 2001). The form factors of $T_{\mathrm{g} 1}$ and $T_{\mathrm{g} 2}$ glows irradiated with $7.527 \mathrm{KGy}$ are found to be 0.51 and 0.49 , respectively. The trap parameters are calculated using glow curve shape method (modified by Chen) and tabulated in table 1 . The detailed description of calculations is discussed in our previous communication (Nagabhushana et al 2008). The activation energy and frequency factors are estimated to be $1.01 \mathrm{eV}, 1.52 \mathrm{eV}$ and $7.51 \times$ $10^{9} \mathrm{~s}^{-1}, 2.68 \times 10^{11} \mathrm{~s}^{-1}$ for $T_{\mathrm{g} 1}$ and $T_{\mathrm{g} 2}$, respectively.

\section{Conclusions}

Photoluminescence and thermoluminescence of polycrystalline aluminum oxide phosphor synthesized by combustion technique using urea as fuel are studied. The $\gamma$-rayed samples show a broad PL emission with peak at $465 \mathrm{~nm}$ and doublet $\mathrm{Cr}^{3+}$ emission at 679 and $694 \mathrm{~nm}$ are observed. The $465 \mathrm{~nm}$ emission is attributed to $F_{2}^{+}$defect centre formed during $\gamma$-irradiation. Two well resolved TSL glows with peaks at $210^{\circ} \mathrm{C}$ and $365^{\circ} \mathrm{C}$ are observed in $\gamma$-irradiated samples. The low temperature TSL glow peak $\left(210^{\circ} \mathrm{C}\right)$ is attributed to $F$-centres and the high temperature TSL glow peak $\left(365^{\circ} \mathrm{C}\right)$ is tentatively attributed to $F_{2}^{+}$defect centre. The order of kinetics for these two TSL glow peaks for 7.527 KGy $\gamma$-rayed samples are calculated to be 0.51 and 0.49 , respectively which confirm the second order kinetics. The high temperature TSL peak $\left(T_{\mathrm{g} 2}\right)$ shifts slightly towards lower temperature with increase in the doses. The TSL intensity in the present powder form of $\mathrm{Al}_{2} \mathrm{O}_{3}$ increases with increase in $\gamma$-ray dose. These studies suggested that the TSL glow peak at $210^{\circ} \mathrm{C}$ in combustion synthesized aluminum oxide can be considered as radiation dosimetric peak after studying the dosimetric characteristics viz. fading, annealing behaviour, energy response, reproducibility etc.

\section{Acknowledgements}

The authors express their sincere thanks to Dr Lakshminarasimhan and Sri T S Parthasarathi, ISRO Satellite Centre, Bangalore, for constant encouragement and help during $\gamma$-irradiation. Also, Prof. Ramani, Chairperson, Department of Physics, Bangalore University, Bangalore, is acknowledged for her constant encouragement. One of the authors (KRN) is grateful to Inter University Acce- 
lerator Centre, New Delhi, for providing a fellowship under UFUP (No. 37314) scheme.

\section{References}

Bos A J J 2001 Nucl. Instrum. Meth. B184 3

Chithambo M L, Sendezera E J and Davidson A T 2002 Radiat. Protect. Dosim. 100269

Horowitz Y S, Avila O and Rodriguez-Villafuerte M 2001 Nucl. Instrum. \& Meth. B184 85

Kingsley J J and Patil K C 1988 Mater. Lett. 6427

Kinsman K M, McKittrick J, Sluzky E and Hesse K 1994 J. Am. Ceram. Soc. 772866

Kortov V S, Nikiforov S V, Milman I I and Moinseykin E V 2004 Radiat. Meas. 38451

McKeever S W S, Akselrod M S, Colyott L E, Agersnap Larsen N, Polf J C and Whitley V 1999 Radiat. Protect. Dosim. 84163
Mimani T and Patil K C 2001 Mater. Phys. Mech. 4134

Nagabhushana K R, Lakshminarasappa B N, Chandrappa G T, Haranath D and Fouran Singh 2007 Radiat. Eff. \& Defect. Sol. 162325

Nagabhushana K R, Lakshminarasappa B N and Fouran Singh 2008 Radiat. Meas. doi:10.1016/j.radmeas.2008.04.035 (in press)

Rao C N R 1993 Mater. Sci. and Eng. B18 1

Rieke J K and Daniels F 1957 J. Phys. Chem. 51629

Summers G P 1984 Radiat. Protect. Dosim. 869

Toyoda Taro, Obikawa Takashi and Shigenari Takeshi 1998 Mater. Sci. \& Eng. B54 33

Veitch C D 1991 J. Mater. Sci. 266527

Yukihara E G, Gaza R, McKeever S W S and Soares C G 2004 Radiat. Meas. 3859

Zhang C X, Tang Q, Lin L B and Luo D L 2006 Radiat. Protect. Dosim. 119402

Zhang Y and Stangle G C 1994 J. Mater. Res. 91997 